\title{
Great Power of Positive Thinking When Applied Correctly
}

\author{
Xiuyi Jia ${ }^{1, a}$ \\ The High School Affiliated To Renmin University Of China, 100010, Beijing, China \\ *Corresponding author. Email: angela@cas-harbour.org
}

\begin{abstract}
This article summarizes the general advantages of positive psychology, optimism and the correct usage of it. During the past decades, topics revolving around positive psychology have aroused attentions of the public. Misinterpretations are frequent, whereby people are misled. Several literatures show the benefits of correct applications of optimism including healing emotional issue, faster and better recovery, and preventative effect. Another research has provided evidence that people cannot systematically fool himself. Therefore, the suitable approaches are introduced. This article studies different groups of people, including patients, teenagers, and people with longevity. Distinct measures are taken to conduct respective experiments, mostly through surveys and interviews. Additionally, the article is based on ample authoritative researches published within decades and represents the author's personal aspect of positive psychology. In conclusion, positive psychology might be beneficial to put forward the way to apply it in daily lives.
\end{abstract}

Key words: Positive psychology, optimism, correct usage, authoritative research, self-confidence, optimism

\section{INTRODUCTION}

To Aristotle, happiness is the ultimate end and the purpose of human existence, which is achieved by exercising good virtue over the course of one's lifetime [1]. To him, it was a truth as the idea was delivered far before psychology existing as a proper science, but was actually validated to be true later. We, human beings, evolved greatly for the past thousands of years for one purpose, survival. Therefore, other needs derived. According to Maslow's Pyramid of needs, the purpose of living has become more complex as humans demand emotional fulfillment, dignity and self-accomplishment besides physiological needs and safe environment [2]. All could be achieved through exercising good virtue, which is positive thinking. Only if exercising good habits, the goal can be achieved, which means that everyone needs to follow certain rules when practices. In other words, one should learn how and when to utilize positive emotions correctly. This paper argues that positive thinking is powerful, and people should make good use of it in the right way.

\section{ANALYSIS ON THE BENEFITS OF POSITIVE THINKING}

\subsection{Resilience to Emotions}

First and foremost, the direct benefit of positive thinking is resilience. Positive thinking reinforces our ability to handle pressure. People who are resilient, adjust faster from negative emotions [3] and are able to deal with higher level of stress. The term resilience originates from a property of metals, which means the capacity to reverse its shape after being bent or stretched. In psychology, resilience represents a capacity of whether one is competent to heal or recover from negative emotions more efficiently. Many experiments conducted in the last decades show that, those people with strong resilience can gain positive energy even when they are under great pressure. What is more, people who are resilient also have smaller likelihood to become criminals. A positive way of facing trauma guarantees a bright future for an individual, especially when the individual is in adolescence. Researches also find that the teenagers, who have experienced serious trauma when they were young and eventually have overcome it with positive thinking, later all turned out to be resilient people who can handle anxiety, indicating that resilience is a trait which can be required. It exemplified for the fact that resilience is a trait of people that can be acquired through experience. Positive thinking can enhance people's ability to carry heavy workloads and rapid working pace [4]. As demonstrated in the picture below, resilience is an ability to shift emotions. The person who stands against the springs suffers a lot, mimicking those who do not have resilience in their emotions. The one lying on the floor is presented to be cozy because he can adjust well. 


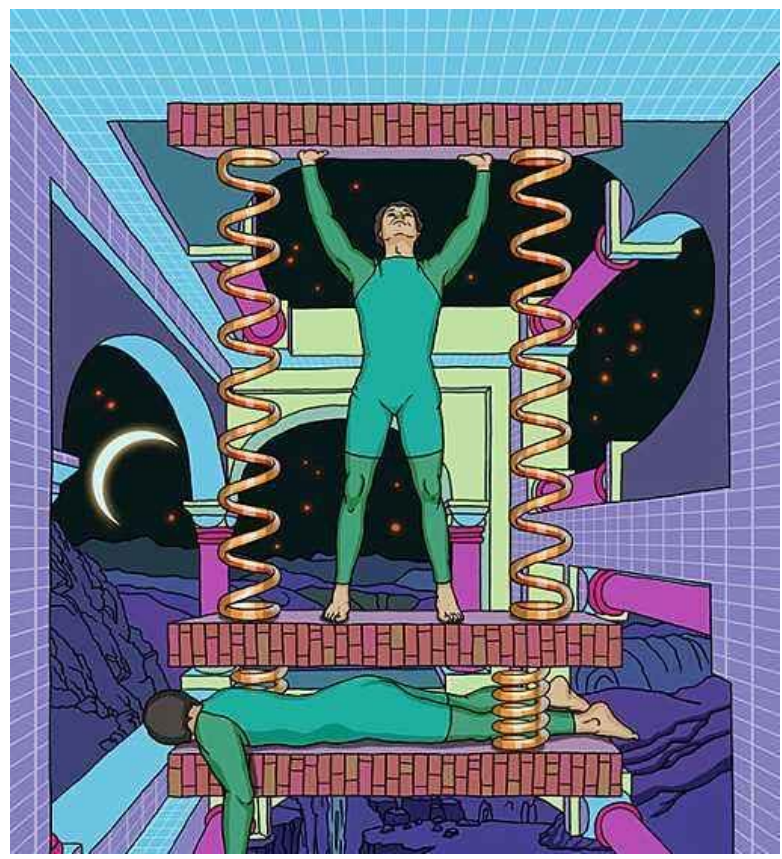

Figure 1. Positive thinking keeps us resilient to negative emotions (from zihua.com.cn)

\subsection{Pull People Back From Negative Emotions}

Secondly, positive emotions can pull people back from negative emotions. Joyful emotions can accelerate the alleviation from cardiovascular changes caused by enduring anxiety. This process is termed Undoing Effect. Negative emotions, for instance, sadness, surprise and rage are usually produced to stop a certain action, reduce the tendency to certain behavior, or alert the body, which evokes the body to intensify activity to match new environmental challenges. Therefore, it creates unbalanced physiological activity inside, mostly cardiovascular changes. Positive emotions show up as a sign to relax the body and ease the cardiovascular conditions, undoing them and reserving back to the baseline. Fredrickson and his colleagues verified this assertion by an experiment. They firstly informed that human were subjected to do a one-minute speech in order to induce the anxiety. Then the experimenter randomly divided those subjects into four groups, who respectively watched short sections of movies that stimulated joy, fulfillment, sadness and nothing. The last one was set as a blank test sample. The result showed the person who watched the first two films recovered considerably faster than the latter two, and the data proved that people who watched movies that provoked sad feelings recovered the slowest. In addition, those who smiled when watching films recovered faster than those who did not smile or laugh at all. Not only physically, positive emotions can also regain the way of thinking from the narrow thinking provoked by anxiety. Consequently, it is reasonable to draw the conclusion that joyful emotions undo negative ones. This solves the concerns of ample people. This is a direct discovery that can change people's lives [5].

\subsection{Prevent Diseases and Decrease Their Risks}

Thirdly, positive thinking can prevent diseases as well as decrease the risk of having them. Universally, health counts as the basic and fundamental needs to humans. Positive mindset has a preventive impact toward pathogen infection and other illness, particularly cardiovascular diseases. Optimistic people with less emotional fluctuations have relatively lower and much stable blood pressure than those living in anxiety who are relatively pessimistic [6]. Individuals who have intimate and warm relationships with their family are less likely to be diagnosed with high blood pressure, coronary artery disease and intemperance [7]. As shown in figure 2, people who have intimate relationships outlive others by increasing resistance to diseases. A large number of medical studies have also shown the ability of positive emotions to prevent diseases. Treating diseases with confidence, optimism, calmness and adamancy can influence neuro-regulation and regulation of incretion, through brain control of ganglion cerebral and thymus gland. Therefore, it enhances the performance of cell mediated immunity, humoral immunity and other mechanisms, in order to reinforce the capacity to fight diseases. This process is called preventive effect of positive emotions [8]. Besides those characters mentioned above, subjective joy impacts immune system as well. People who subjectively feel happy and fulfilled do have greater level of health and efficiency at working. Laughter and humor are two main indicators in most of the related experiments. Humor is considered as a cognitive phenomenon for people to deal with stress. People who usually utilize humor to handle pressure often have much longer life span, because humor increases the number of salivary immunoglobulin $\mathrm{A}$, which is the first defense of respiratory system of human bodies, and further strengthens our immune response [9].

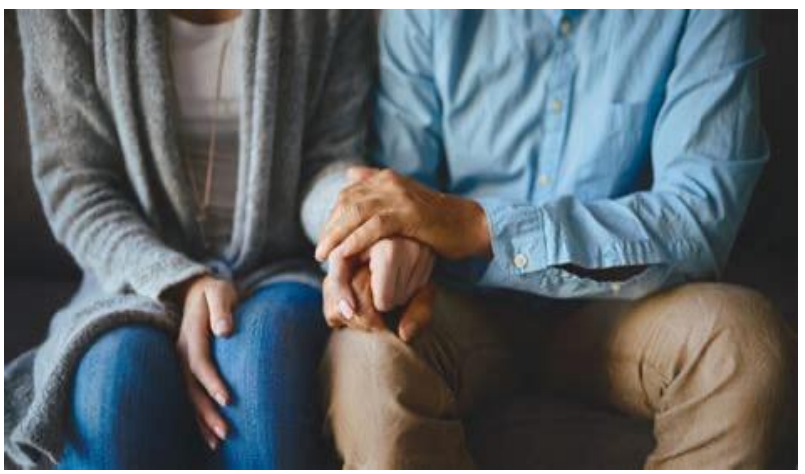

Figure 2. Family and friends give us warmth that help fight against disease and expand our live spans.

(Retrieved from Myocn.net) 


\subsection{Optimism Enhances Overall Health}

The fourth benefit is that optimism is propitious to our physical health. Relating to the previous paragraph, positive emotions can not only prevent illnesses from happening, but also accelerate recovery and reduce the possibility of recrudescence. Scientific researches have already proved that optimism leads to lower possibility of illness and high speed of healing. For instance, after a heart transplant, positive expectation usually suggests greater health. Other major surgery also shows the same results. Cancer is vindicated to be another example. Patients with positive emotions end up their lives in a much healthier way than those do not have [10]. Researchers studied those who lost their spouse, and among them, the ones who overcame this tragedy and once again found a new purpose of life, had longer life span [11]. Furthermore, it is well known in medical field that full disappearance of symptoms does not mean full recovery. Still, there are potential of recrudescence. Some studies about survivors verified this claim as well. Lower anxiety and depression state can have positive influence on their longevity. According to Affleck, he found out people who acquired new meaning of life after the first heart attack, had less potential of the second heart attack [12]. Supports from the society and family members play an important role in lowering negative mental conditions. There are a great amount of experiments involving optimistic, related to copious branches of disease and trauma, and all proven to support this idea. Dr. Fava and her colleagues found a health session for people just pulling through a major surgery, to enhance their acknowledgments and understandings of daily lives. Those who have joined this session have lower recrudescence rate [13]. This experiment also exemplified for the claim that positive emotion was a cognitive phenomenon, an extrinsic character that could be acquired through practice. Therefore, one's cognition influences his or her health.

\section{DISCUSSION}

In spite of the content above, there are other things worth to mention. Being positive is beneficial and very intriguing. However, if it is used incorrectly, there will be negative consequences that are opposite to the original purposes.

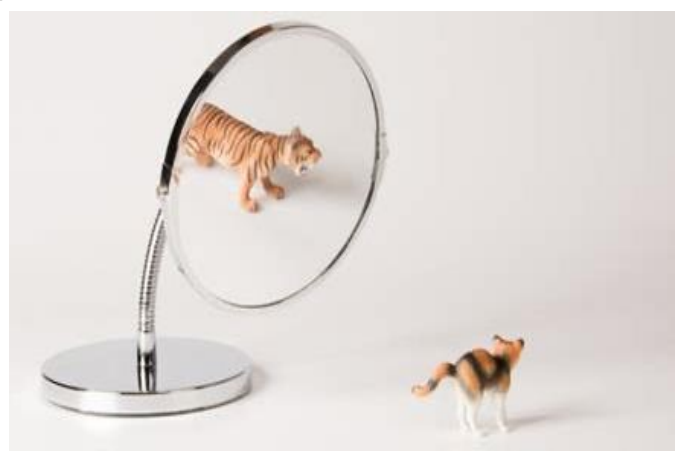

Figure 3. Optimism makes us better. (Retrieved from Spirituality)

\subsection{Positive Psychology Is Approachable}

Optimism is a part of personality, and it is possible to gain extrinsically. Some people could have intrinsic talents of being optimistic in personality, but some could not. It is a natural phenomenon. It is a good property that people should try to gain, though it may take a long time. Difficulties mainly surround introspection, which is an inevitable mind activity of human beings and works as a detector of lies. Without it, self-delusion is much easier. With some of this metal cognition, self-deception becomes a much more subtle and complex endeavor. It will be successful only if self-belief matches the individual's behaviors in real life. Depressed people often sink in a world of sorrow, as they enjoy the pain in a way, or for it is just much simpler to give up. However, being diffident actually has negative outcomes. People who think minor of themselves do perform worse than the average, on account of low motivation and low self-esteem. In other words, they do not believe in themselves and do feel that they deserve the bad results of their work and study [14]. When confidence and positive thinking are difficult to attain for the fact that people may not be born with it, one can still acquire this advantageous trait through practice. Seeking help from parents or therapists is possibly the best way to achieve this goal. Therapists can provide a set of rules in the respects of gathering, interpretation, and encoding into memory of self-relevant information, to pull people out of the self-traps circle. Entrapping in negative, depressed emotion, low self-esteem or diffident state is dangerous. The central means of training is to become optimistic and to build up a new self-image. Through recollecting memory, self-reversing attribution and rehearsal of event, one can achieve the aim although it takes time and patience to practice.

\subsection{Correct Usage of Positive Psychology}

It is necessary to understand what optimism is and learn when and how to apply it correctly to serve our purposes. Firstly, positive thinking is a kind of mental attitude in which people expect good and favorable results. Also, a positive mind waits for happiness, health and a happy ending in any situation. However, it is different from self-deception. Self-deception happens when one knows the valid fact but chooses to ignore it and tells himself or herself otherwise. Blindly deceiving harms people in a mental way.

Currently, positive thinking is a very popular topic, which consequently leads to lots of psychologists or writers to publish books and give speech about it. It is advocated in books to "look at the bright side" (the most classic one is the half glass of water example), and to forget the bad things. In some cases, it is effective. However, numerous 
studies showed that positive thinking cannot be applied in all circumstances. In certain situations, "we need to embrace how we feel and accept who we are," instead of avoiding them. Under those conditions, continuous delusion is malign. However, whether one should apply self-delusion or not is determined by the cost of doing so. In the absence of adverse recollections, if the likelihood of cost of realization is low or insufficient to discourage self-delusion, the cost of deception is near zero. If the possibility of realization is high and such events may happen frequently, one should not imply deception in order to protect himself or herself from further damages.

\subsection{Expectation for Future of Psychology}

In recent decades, positive psychology becomes a known and popular topic all over the world, fusing into our daily live. It draws the attention of a number of newspapers, such as "We Media", broadcast, websites and books. Unfortunately, many media have published baseless arguments or false arguments. It is difficult to distinguish whether the claims are true or not, whereby it may harm audience. Therefore, the author expects that the future of public psychological articles be more credit and research-based. There are many remaining mysteries to be solved, such as the explanations for love and hate. However, the future for psychology is promising, and mysteries are waiting to be revealed in the following decades.

\section{CONCLUSION}

Positive thinking can be beneficial for people in many ways. With it, one can perform well under high pressure and be insusceptible to negative emotions. In addition, people can also recover from anxiety faster and prevent disease better. Therefore, the likelihood of recovery from illness is higher and the risk of recrudescence is lower. Positive thinking is a relatively accessible, practical, and effective way of improving living standard and physical health. It serves people the best solution when applied in a scientific way, otherwise it could lead to bad results. All in all, positive thinking is a double edged sword, which could fight against the enemy with proper application, or harm oneself if used unwisely.

\section{ACKNOWLEDGMENT}

First and foremost, I would like to show my deepest gratitude to my teachers and professors in university, who have provided me with valuable guidance in every stage of the writing of this thesis. Further, I would like to thank all my friends and families for their encouragement and support. Without all their enlightening instruction and impressive kindness, I could not have completed my thesis.

\section{REFERENCES}

[1]Aristotle(n.d.)[Online]Available:https://www.pursuit-of -happiness.org/history-of-happiness/aristotle [Retrieved on March 27, 2020]

[2] Maslow, A. H. (1943). A theory of human motivation. Psychological Review, 50(4), 370-96.

[3] American Psychology Association Help Center:The road to resilience: What is resilience[Online] Available:http://www.apahelpcenter.org/fea-turedtopics/fe ature.php-id=6\&amp;ch=2, 2002 [Retrieved on March 27, 2020]

[4] Fergusson D. M., Lynskey M. T. Adolescent resiliency to family adversity. Journal of Child Psychology and Psychiatry, 1996, 37, 281-292.

[5] Fredrickson B. L., Levenson R. W. Positive emotions speed recovery from the cardiovascular sequelae of negative emotions.Cognition and Emotion, 1998, $12: 191-220$

[6] Rikknen K. A., Flory J. D., Owens J. F., Gump B. B., et al. Effects of optimism, pessimism, and trait anxiety on ambulatory blood pressure and mood during everyday life.Journal of Personality and Social Psychology, 1999, 76:104-113.

[7] Russek L. G., Schwartz G. E. Feelings of parental caring predict health status in midlife: A35-year follow-up of the Harvard Mastery of Stress Study.Journal of Behavioral Medicine, 1997, 20:1-13.

[8] Fitzgerald T. E., Tenn H., Affleck G., Pransky G. S. The relative importance of dispositional optimism and control appraisals in quality of life after coronary artery bypass surgery.Journal of Behavioral Medicine, 1993, $16: 25-43$

[9] Stone A. A., Cox D. S., Valdimarsdottir H., Neale J. M., et al. Secretory $\operatorname{IgA}$ as a measure of immune competence.Journal of Human Stress, 1997, 13:136-140.

[10] Spiegel D. Effects of psychosocial treatment in prolonging cancer survival may be mediated by neuroimmune pathways.Annals of the New York Academy of Sciences, 1998, 840:674-683.

[11] Keltner D., Bonanno G. A. A. Study of laughter and dissociation:Distinct correlates of laughter and smiling 
during bereavement.Journal of Personality and Social Psychology, 1997, 73:687-702.

[12] Taylor S. E., Kemeny M. E., Reed G. M., Bower J. E., Gruenewald T. L. Psychological resources, positive illusions, and health.American Psychologist, 2000, 55:99-109.
[13] Affleck G., Tennen H., Groog S. Casual attribution, Perceived benefits, and morbidity after a heart attack:An8-yeas study.Journal of Consulting and Clinical Psychology, 1987, 55:29-23.

[14] Fava G. A. Well-being therapy:Conceptual and technical issues.Psychotherapy and Psychosomatics, 1999, 68:171-179. 